\title{
Validation of the Resilience Scale for Adolescents in High School in a Spanish Population
}

\author{
María del Carmen Pérez-Fuentes ${ }^{1}\left(\mathbb{C}\right.$, María del Mar Molero Jurado ${ }^{1, *} \mathbb{C}^{(}$, \\ Ana Belén Barragán Martín ${ }^{1}{ }^{\mathbb{D}}$, Isabel Mercader Rubio ${ }^{1}$ and José Jesús Gázquez Linares ${ }^{1,2, *}$ \\ 1 Department of Psychology, University of Almería, 04120 Almería, Spain; mpf421@ual.es (M.d.C.P.-F.); \\ abm410@ual.es (A.B.B.M.); imercade@ual.es (I.M.R.) \\ 2 Department of Psychology, Universidad Autónoma de Chile, Región Metropolitana, \\ Providencia 7500000, Chile \\ * Correspondence: mmj130@ual.es (M.d.M.M.J.); jlinares@ual.es (J.J.G.L.); Tel.: +34-950-015-598 (M.d.M.M.J.)
}

Received: 28 February 2020; Accepted: 31 March 2020; Published: 7 April 2020

\begin{abstract}
Resilience is a personal competence that facilitates coping with adversity and forms part of an individual's psychosocial adjustment. Therefore, this construct has an important role in adolescent development. Youths with high levels of resilience usually show less risk of behavioral disorders, low academic performance or interpersonal conflicts. The objective of this study was to validate the Resilience Scale for Adolescents (READ) in a Spanish population, and test whether this questionnaire is valid for different cultures and societies. The sample comprised $317 \mathrm{high}$ school students aged 13 to 18 years old with an average age of 14.93, in the province of Almería (Spain). The Resilience Scale for Adolescents was administered for this. Based on exploratory factor analysis and the various previous studies undertaken on validation of this instrument, four models were proposed, of which the original READ model showed the best fit. Validation of this scale showed good internal consistency and high reliability on five factors: Family Cohesion, Personal Competence, Social Competence, Social Resources and Orientation toward Goals. It is considered a valid instrument for evaluating the various factors of resilience and can help determine the education factors contributing to the process of positive adaptation in adolescence.
\end{abstract}

Keywords: resilience; READ; adolescents; validation; education

\section{Introduction}

Adolescence is characterized by knowledge and experience acquired and by the changes that take place during the three stages (early, middle and late) it can be divided into [1,2]. Psychological, biological and social changes influence the subjective wellbeing of the adolescent [3-5]. To date, most studies in this area have been carried out in adult populations, and only a few have been undertaken with adolescents [6]. Subjective wellbeing has awakened strong interest in psychology, and, therefore, studies should be associated with satisfaction with life and the happiness of individuals [7].

Among the psychological factors that influence subjective wellbeing is resilience, which refers to a phenomenon or progress in positive adaptation, regardless of negative or traumatic experiences undergone [8]. According to Masten [9] resilience is a "phenomenon characterized by good outcomes" (p. 228). Bonanno [10] mentioned that resilience is a personal competence that benefits functioning in the face of adversity. This construct forms part of the individual's psychosocial adjustment, which depends as much on it as self-concept [11], and the two counteract perceived social vulnerability [12]. Resilience is also considered a protective factor [13], and is affected by interaction between genetic and environmental factors [14]. 
Resilience in adolescence leads to overcoming difficulties through coping strategies [15]. Thus, adolescents with this characteristic can overcome the risks of their progression during this stage more easily [16]. That is, youths with high levels of resilience have less risk of mental illness, behavioral disorders, low academic performance or interpersonal conflicts $[17,18]$. Resilience also positively affects life development and experiencing emotions [19].

Resilience can be explained by several factors: individual positive factors, family and other support networks outside the family. Personality factors also act as mediators on the effect of resilience, and improvement in it is affected by coping styles [20]. Possessing this characteristic is linked to good psychological wellbeing, good state of mental health [21] and, therefore, high levels of quality of life [22].

\section{Evaluating Resilience}

Resilience can be measured by its three categories and, therefore, the development of validated measures with good reliability indices in both intrapersonal and personal factors are necessary to be able to respond to these categories. There are several resilience scales for different populations, such as the Spanish Resilience Questionnaire [23], and other scales for different areas, for example, for the family, the Inventory of Resilience for mothers [24] and the Brief Scale of Resilience to Children's Behavior Problems, addressing evaluation of resilience of parents [25].

Other studies have used the Connor-Davidson Scale of Resilience (CD-RISC) which measures the ability to fight traumatic stress [26]. This instrument has been applied to a general population, psychiatric patients, patients with disorders or anxiety and in primary care, showing good internal consistency and high reliability. Several years later, this same scale was adapted by Yu et al. [27] in a sample of Chinese adolescents, where the five original factors of the scale were combined in an overall resilience scale. It was validated in Spanish by Serrano et al. [28] in an older population. Campbell-Sills and Stein [29] reduced this scale in a brief version called the 10-item CD-RISC, which was adapted to Spanish and validated in a university population [30,31]. In recent years, resilience has awakened greater interest in research, as it facilitates mechanisms for coping better with difficult situations [32]. Even though it is one of the constructs studied in adults [33], university students [34] and children [35], the instruments for evaluating adolescent populations only began to be designed 12 years ago.

In view of this need to design a resilience scale for adolescents, Hjemdal et al. [13] developed the Resilience Scale for Adolescents (READ) for a Norwegian adolescent population aged 13 to 15, which showed good psychometric properties and a negative relationship with depressive symptoms. This scale may be used as a predictor of a good state of health, and to evaluate protective factors linked to signs of depression in an adolescent population [32]. However, it should be used with caution, since the authors reported that the results were found for a specific sample and age, which would be a limitation, as it only considers early adolescence. Von Soest, Mossige, Stefansen, and Hjemdal [36] designed a 23-item version for adolescents aged 18 to 20 to evaluate the resilience factors with few items, and this version is extensive to all ages of adolescence.

A study by Windle, Bennett, and Noyes [37] in a review of several scales, found that the READ had higher content and construct validity than other scales. This instrument has been adapted to other countries, such as Italy [38], Mexico [39] and Norway [40].

Another of the instruments is the Adolescent Resilience Questionnaire (ARQ), which is based on the multidimensional nature of resilience, with 12 scales which measure the factors in individual, family, peer, school and community domains [41]. This instrument has also been validated in the Romanian context [42], in Spanish adolescents [43] and in young Iranians [44].

Not only are there instruments for evaluating middle and late adolescence, but also for evaluating early adolescence. Sahin and Karatas [45] validated the Resilience Scale for Early Adolescence (RSEA) in a sample of Turkish adolescents.

In the light of the importance of resilience to development of the adolescent population, highly reliable, validated instruments must be designed and adapted to be able to measure it. Thus, the 
purpose of this study was to find out whether the READ questionnaire is valid for application in different cultures and contexts.

\section{Materials and Methods}

\subsection{Participants}

This cross-sectional study was carried out with a random cluster sample. The sample was made up of a total of 317 participants from two high schools in the province of Almeria (Spain). The students were 13 to 18 years of age $(M=14.93$; standard deviation $(S D)=1.06)$. Boys made up $50.8 \%(n=161)$ of the sample and had a mean age of $14.85(\mathrm{SD}=1.00)$. Girls made up $49.2 \%(\mathrm{n}=156)$ and had a mean age of $15.01(\mathrm{SD}=1.11)$. The sample was distributed over two grades: $61.5 \%(n=195)$ were in their third year of high school and $38.5 \%(n=122)$ in their fourth year.

The family employment situation was distributed as follows: in $22.1 \%(n=70)$, only the father was working, in $11.7 \%(n=37)$, only the mother was working, and in $60.3 \%(n=191)$ both were working. In $5.4 \%(n=17)$ both were either unemployed or retired.

\subsection{Instruments}

An ad hoc questionnaire was designed to collect the sociodemographic data (age, sex, grade, parents' employment status).

Resilience Scale for Adolescents (READ). The Spanish-language adaptation and validation in a Mexican population [39] of the original resilience scale for adolescents by Hjemdal et al. [13] was used in this study. The scale is comprised of five factors: Personal Competence (I feel competent), Social Competence (I make new friends easily), Family Cohesion (I feel good with my family), Social Resources (I know how to reach my goals) and Orientation toward Goals (I have some friends and relatives who often encourage me), distributed in 22 items. Cronbach's alpha was 0.85 on the Family Cohesion scale, 0.69 on Personal Competence, 0.80 on Social Competence, 0.85 on Social Resources, and 0.76 on Orientation toward Goals. The internal consistency of the instrument was 0.90 .

\subsection{Procedure}

To carry out this study, the high school principals and participants had the objectives and data usage explained to them. The students were also told that participation was voluntary, and given the instructions necessary for filling out the questionnaire. They were informed of the anonymity of their answers and confidentiality of their data. The participants had the opportunity to give their informed consent to comply with research ethics.

Although the scale used had been validated in Mexican adolescents, the original scale in English was translated into Castilian Spanish, using the back-translation method, such that the scale provided by the authors [39] already translated into Spanish was again translated back into English for retranslation into Spanish, and thus its conceptual equivalence and naturalness evaluated. Finally, it was reviewed by experts for adequacy and evaluation of the back-translation.

\subsection{Data Analysis}

First, the normality of the sample was confirmed following the criterion of Finney and DiStefano [46]. Based on exploratory factor analysis and prior validation studies of the same and other versions of the questionnaire, three models were proposed, the original (READ) model, the model found by exploratory factor analysis (READ-R4) and the model with forced distribution in five factors (READ-R). Confirmatory Factor Analysis was performed on the different models, taking the following goodness-of-fit indices as measures: $\chi^{2} / \mathrm{df}$, comparative fit index (CFI), Tucker-Lewis index (TLI), root mean square error of approximation (RMSEA) at a $90 \%$ confidence interval (CI). The $\chi^{2} / \mathrm{df}$ ratio was used considering below five as acceptable [47], for the CFI and IFI over or near 0.95 and for the RMSEA inner values very near 0.06 [48]. 
The Cronbach's alpha [49] and combined reliability were calculated to test the reliability of the instrument. An analysis was also done to support invariance across sex of the factor structure proposed. First goodness-of-fit of both subsamples was tested separately (Models M0a-Boy and Model M0b-Girl). The resulting four nested models were evaluated: (a) Model 1. Both subsamples considered simultaneously allowing for free estimation of parameters. (b) Model 2. With metric invariance. (c) Model 3. With scalar invariance. (d) Model 4. Strict invariance.

There was no consensus criterion to determine the criteria to be used to evaluate the difference in fit of the nested models [50]. For evaluation of fit, this study focused on the $\Delta C F I$. Thus, the model is completely invariant if the $\triangle \mathrm{CFI}$ is below 0.01 [51].

The analyses were performed with the SPSS statistical package for Windows version 23.0 and AMOS 22.

\section{Results}

\subsection{Preliminary Analyses}

The correlations of the 22 items, the means, standard deviations, skewness and kurtosis are shown in Table 1. It may be observed that most of the correlations were statistically significant and the kurtosis and skewness of each variable were acceptable, so extraction of principal components with direct Oblimin rotation, which enables correlation of existing factors, seemed justified.

\subsection{Exploratory Factor Analysis}

The principal component analysis (Determinant $p=4.84$ shows intercorrelation between variables) of the READ scale revealed the existence of four components with eigenvalues over 1 . The scree test showed the adequacy of rotation with four factors with values of 3.38, the following two being barely below 1 , with 0.96 and 0.91 , although they are far from the seventh with a score of 0.81 (Figure 1). After factor analysis, the items with factor saturations over 0.40 were selected from the rotated component matrix (varimax rotation). The four-factor distribution of the items is shown in Table 2 (Model READ-4R).

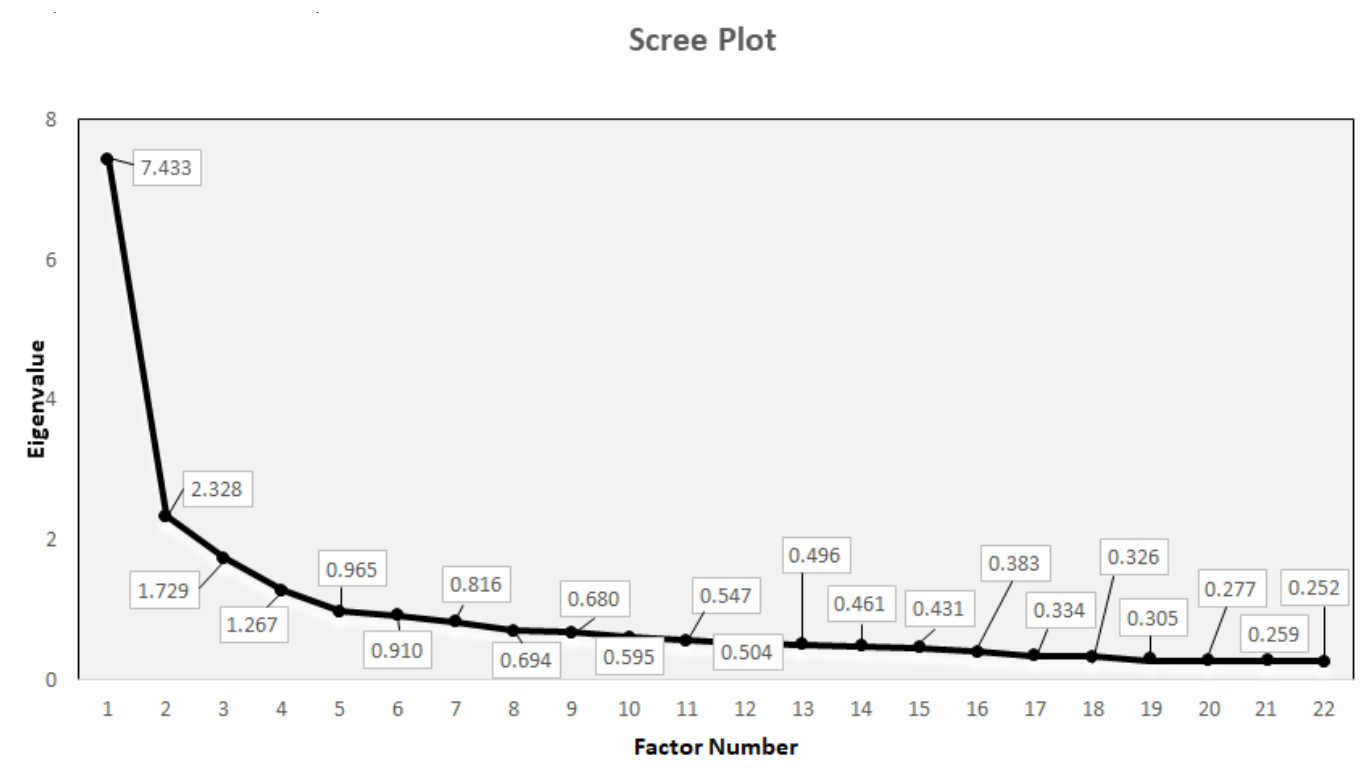

Figure 1. Factor analysis scree plot. 
Table 1. Correlation analysis of items. Descriptive statistics

\begin{tabular}{|c|c|c|c|c|c|c|c|c|c|c|c|c|c|c|c|c|c|c|c|c|c|c|}
\hline & 1 & 2 & 3 & 4 & 5 & 6 & 7 & 8 & 9 & 10 & 11 & 12 & 13 & 14 & 15 & 16 & 17 & 18 & 19 & 20 & 21 & 22 \\
\hline 1 & 1 & * & & & & & & & & & & & & & & & & & & & & \\
\hline 2 & $0.536^{* *}$ & 1 & & & & & & & & & & & & & & & & & & & & \\
\hline 3 & $0.486^{* *}$ & $0.544^{* *}$ & 1 & & & & & & & & & & & & & & & & & * & & \\
\hline 4 & $0.333^{* *}$ & $0.402^{* *}$ & $0.412^{* *}$ & 1 & & & & & & & & & & & & & & & & & & \\
\hline 5 & $0.550^{* *}$ & $0.612^{* *}$ & $0.531^{* *}$ & $0.534^{* *}$ & 1 & & & & & & & & & & & & & & & & & \\
\hline 6 & $0.486^{* *}$ & $0.528^{* *}$ & $0.474^{* *}$ & ${ }^{*} 0.315^{* *}$ & $0.613^{* *}$ & 1 & & & & & & & & & & & & & & & & \\
\hline 7 & $0.325^{* *}$ & $0.288^{* *}$ & $0.192^{* *}$ & ${ }^{*} 0.122^{*}$ & $0.198^{* *}$ & $0.275^{* *}$ & 1 & & & & & & & & & & & & & & & \\
\hline 8 & $0.157^{* *}$ & $0.173^{* *}$ & $0.118^{*}$ & $0.116^{*}$ & 0.078 & $0.185^{* *}$ & $0.440^{* *}$ & 1 & & & & & & & & & & & & & & \\
\hline 9 & $0.243^{* *}$ & $0.231^{* *}$ & $0.138^{*}$ & $0.168^{* *}$ & $0.116^{*}$ & $0.151^{* *}$ & $0.383^{* *}$ & $0.716^{* *}$ & 1 & & & & & & & & & & & & & \\
\hline 10 & $0.282^{* *}$ & $0.244^{* *}$ & $0.245^{* *}$ & ${ }^{*} 0.164^{* *}$ & $0.197^{* *}$ & $0.217^{* *}$ & $0.408^{* *}$ & $0.449^{* *}$ & $0.518^{* *}$ & 1 & & & & & & & & & & & & \\
\hline 11 & $0.228^{* *}$ & $0.171^{* *}$ & 0.058 & 0.097 & 0.098 & $0.233^{* *}$ & $0.443^{* *}$ & $0.352^{* *}$ & $0.314^{* *}$ & $0.470^{* *}$ & 1 & & & & & & & & & & & \\
\hline 12 & $0.213^{* *}$ & $0.134^{*}$ & 0.095 & 0.099 & $0.164^{* *}$ & $0.150^{* *}$ & $0.203^{* *}$ & $0.198^{* *}$ & $0.208^{* *}$ & $0.216^{* *}$ & ${ }^{*} 0.203^{* *}$ & 1 & & & & & & & & & & \\
\hline 13 & $0.142^{*}$ & $0.130^{*}$ & $0.135^{*}$ & 0.063 & $0.146^{* *}$ & $0.184^{* *}$ & 0.098 & $0.155^{* *}$ & $0.146^{* *}$ & $0.247^{* *}$ & ${ }^{*} 0.251^{* *}$ & $0.196^{* *}$ & 1 & & & & & & & & & \\
\hline 14 & $0.251^{* *}$ & $0.261^{* *}$ & $0.248^{* *}$ & $0.248^{* *}$ & $0.278^{* *}$ & $0.280^{* *}$ & $0.315^{* *}$ & $0.237^{* *}$ & $0.214^{* *}$ & $0.315^{* *}$ & $0.405^{* *}$ & $0.343^{* *}$ & $0.481^{* *}$ & 1 & & & & & & & & \\
\hline 15 & $0.220^{* *}$ & $0.283^{* *}$ & $0.282^{* *}$ & ${ }^{*} 0.211^{* *}$ & $0.270^{* *}$ & $0.328^{* *}$ & $0.279^{* *}$ & $0.216^{* *}$ & $0.221^{* *}$ & $0.300^{* *}$ & $0.303^{* *}$ & $0.228^{* *}$ & $0.347^{* *}$ & $0.540^{* *}$ & 1 & & & & & & & \\
\hline 16 & $0.354^{* *}$ & $0.430^{* *}$ & $0.299^{* *}$ & $0.359^{* *}$ & $0.374^{* *}$ & $0.389^{* *}$ & $0.338^{* *}$ & $0.288^{* *}$ & $0.307^{* *}$ & $0.298^{* *}$ & $0.395^{* *}$ & $0.192^{* *}$ & $0.266^{* *}$ & $0.389^{* *}$ & $0.407^{* *}$ & 1 & & & & & & \\
\hline 17 & $0.271^{* *}$ & $0.339^{* *}$ & $0.197^{* *}$ & $0.247^{* *}$ & $0.325^{* *}$ & $0.321^{* *}$ & $0.269^{* *}$ & $0.272^{* *}$ & $0.242^{* *}$ & $0.172^{* *}$ & $0.273^{* *}$ & $0.239^{* *}$ & $0.203^{* *}$ & $0.266^{* *}$ & $0.288^{* *}$ & ${ }^{*} 0.598^{* *}$ & 1 & & & & & \\
\hline 18 & $0.357^{* *}$ & $0.444^{* *}$ & $0.296^{* *}$ & $0.324^{* *}$ & $0.408^{* *}$ & $0.389^{* *}$ & $0.440^{* *}$ & $0.296^{* *}$ & $0.321^{* *}$ & $0.290^{* *}$ & $0.309^{* *}$ & $0.215^{* *}$ & $0.129^{*}$ & $0.319^{* *}$ & $0.365^{* *}$ & $0.633^{* *}$ & $0.544^{* *}$ & 1 & & & & \\
\hline 19 & $0.366^{* *}$ & $0.475^{* *}$ & $0.278^{* *}$ & ${ }^{*} 0.314^{* *}$ & $0.462^{* *}$ & $0.459^{* *}$ & $0.275^{* *}$ & $0.255^{* *}$ & $0.266^{* *}$ & $0.194^{* *}$ & $0.241^{* *}$ & $0.231^{* *}$ & $0.227^{* *}$ & $0.278^{* *}$ & $0.381^{* *}$ & ${ }^{*} 0.550^{* *}$ & $0.603^{* *}$ & $0.610^{* *}$ & 1 & & & \\
\hline 20 & $0.250^{* *}$ & $0.196^{* *}$ & $0.235^{* *}$ & ${ }^{*} 0.192^{* *}$ & $0.212^{* *}$ & $0.275^{* *}$ & $0.246^{* *}$ & $0.175^{* *}$ & $0.175^{* *}$ & $0.268^{* *}$ & $0.270^{* *}$ & $0.259^{* *}$ & $0.385^{* *}$ & $0.412^{* *}$ & $0.283^{* *}$ & ${ }^{*} 0.333^{* *}$ & $0.222^{* *}$ & $0.311^{* *}$ & $0.364^{* *}$ & 1 & & \\
\hline 21 & $0.336^{* *}$ & $0.255^{* *}$ & $0.229^{* *}$ & ${ }^{*} 0.262^{* *}$ & $0.334^{* *}$ & $0.273^{* *}$ & $0.284^{* *}$ & $0.182^{* *}$ & $0.224^{* *}$ & $0.286^{* *}$ & $0.220^{* *}$ & $0.233^{* *}$ & $0.411^{* *}$ & $0.458^{* *}$ & $0.367^{* *}$ & ${ }^{*} 0.367^{* *}$ & $0.374^{* *}$ & $0.342^{* *}$ & $0.404^{* *}$ & $0.517^{* *}$ & 1 & \\
\hline 22 & $0.268^{* *}$ & $0.224^{* *}$ & $0.208^{* *}$ & ${ }^{*} 0.187^{* *}$ & $0.241^{* *}$ & $0.286^{* *}$ & $0.290^{* *}$ & $0.214^{* *}$ & $0.239^{* *}$ & $0.257^{* *}$ & $0.318^{* *}$ & $0.331^{* *}$ & $0.386^{* *}$ & $0.440^{* *}$ & $0.302^{* *}$ & $0.338^{* *}$ & $0.392^{* *}$ & $0.290^{* *}$ & $0.406^{* *}$ & $0.497^{* *}$ & $0.544^{* *}$ & 1 \\
\hline $\mathrm{N}$ & 316 & 316 & 315 & 316 & 315 & 313 & 314 & 313 & 314 & 316 & 314 & 315 & 314 & 312 & 315 & 316 & 314 & 312 & 314 & 317 & 316 & 317 \\
\hline M & 30.82 & 40.41 & 30.49 & 30.85 & 40.17 & 30.71 & 30.93 & 30.65 & 30.58 & 30.70 & 30.77 & 30.50 & 30.54 & 30.57 & 30.52 & 40.22 & 40.47 & 40.25 & 40.27 & 40.17 & 40.17 & 30.93 \\
\hline SD & 10.141 & 0.933 & 10.130 & 10.112 & 10.064 & 10.177 & 0.984 & 10.240 & 010.259 & 10.090 & 10.064 & 410.101 & 110.125 & 10.232 & 10.157 & 0.959 & 0.908 & 0.984 & 0.916 & 0.949 & 0.923 & 10.045 \\
\hline Skew. & -0.758 & -10.763 & $63-0.526$ & $6-0.728$ & $3-10.292$ & $2-0.661$ & -0.742 & -0.570 & $0-0.519$ & -0.543 & $3-0.615$ & $5-0.314$ & $4-0.523$ & -0.482 & -0.396 & $5-10.101$ & -10.957 & -10.362 & -10.349 & -10.039 & -10.072 & -0.724 \\
\hline Kur. & -0.102 & 20.993 & -0.258 & $8-0.165$ & 510.112 & -0.369 & 0.102 & -0.642 & $2-0.760$ & -0.304 & $4-0.297$ & $7-0.469$ & $9-0.282$ & -0.749 & -0.599 & 0.573 & 30.695 & 10.415 & 10.765 & 0.554 & 10.045 & -0.056 \\
\hline
\end{tabular}


Table 2. Factor structure, communalities (h2) eigenvalues, Cronbach's alpha and percentage of explained variance $(n=316)$. Extraction method: principal components analysis.

\begin{tabular}{|c|c|c|c|c|c|c|c|c|c|c|c|}
\hline & \multicolumn{6}{|c|}{ READ-R Model } & \multicolumn{5}{|c|}{ READ-4R Model } \\
\hline & $\mathrm{F} 1$ & F2 & F3 & F4 & F5 & $h^{2}$ & $\mathrm{~F} 1$ & $\mathrm{~F} 2$ & F3 & $\mathrm{F} 4$ & $h^{2}$ \\
\hline Item 1 & 0.70 & & & & & 0.56 & 0.63 & & & & 0.47 \\
\hline Item 2 & 0.76 & & & & & 0.67 & 0.73 & & & & 0.62 \\
\hline Item 3 & 0.78 & & & & & 0.64 & 0.69 & & & & 0.50 \\
\hline Item 4 & 0.59 & & & & & 0.43 & 0.49 & & & & 0.30 \\
\hline Item 5 & 0.81 & & & & & 0.74 & 0.80 & & & & 0.72 \\
\hline Item 6 & 0.70 & & & & & 0.61 & 0.65 & & & & 0.52 \\
\hline Item 7 & & & & & 0.54 & 0.54 & & & 0.50 & & 0.38 \\
\hline Item 8 & & & & 0.85 & & 0.78 & & & 0.76 & & 0.61 \\
\hline Item 9 & & & & 0.86 & & 0.80 & & & 0.74 & & 0.58 \\
\hline Item 10 & & & & 0.57 & 0.51 & 0.65 & & & 0.64 & & 0.52 \\
\hline Item 11 & & & & & 0.75 & 0.66 & & & 0.43 & & 0.33 \\
\hline Item 12 & & 0.45 & & & & 0.28 & & 0.34 & & & 0.18 \\
\hline Item 13 & & 0.69 & & & & 0.54 & & 0.61 & & & 0.39 \\
\hline Item 14 & & 0.59 & & & 0.52 & 0.65 & & 0.67 & & & 0.53 \\
\hline Item 15 & & & & & 0.52 & 0.50 & & 0.45 & & & 0.36 \\
\hline Item 16 & & & 0.71 & & & 0.70 & & & & 0.62 & 0.61 \\
\hline Item 17 & & & 0.79 & & & 0.71 & & & & 0.67 & 0.57 \\
\hline Item 18 & & & 0.74 & & & 0.73 & & & & 0.66 & 0.65 \\
\hline Item 19 & & & 0.68 & & & 0.72 & 0.41 & & & 0.62 & 0.65 \\
\hline Item 20 & & 0.71 & & & & 0.55 & & 0.59 & & & 0.40 \\
\hline Item 21 & & 0.72 & & & & 0.63 & & 0.65 & & & 0.53 \\
\hline Item 22 & & 0.73 & & & & 0.62 & & 0.64 & & & 0.49 \\
\hline Eigenvalue & 7.43 & 2.33 & 1.73 & 1.27 & 0.97 & & 6.96 & 1.85 & 1.24 & 0.84 & \\
\hline$\%$ explained variance & 33.79 & 10.59 & 7.86 & 5.76 & 4.39 & & 31.62 & 8.43 & 5.62 & 3.81 & \\
\hline Kaiser-Meyer-Olkin & & & & .90 & & & & & 0.90 & & \\
\hline Barlett's Sphericity & & & $31)=2$ & $0.45, p$ & .000 & & & $2^{2}(231)$ & 730.45 & $<0.000$ & \\
\hline Cronbach's Alpha & 0.85 & 0.78 & 0.85 & 0.79 & 0.74 & & 0.85 & 0.80 & 0.80 & 0.85 & \\
\hline
\end{tabular}

Note: the items are listed in decreasing order by saturation. Correlation coefficient visualization $>0.40$. READ-R $=$

Resilience Scale for Adolescents-Revised; READ-4R = Resilience Scale for Adolescents-Revised 4 factors.

Since the theoretical structure of the construct was five factors, principal axis factoring was carried out with varimax rotation with five fixed factors. After factoring, the items with factor saturations over 0.40 were selected from the rotated components matrix (varimax rotation).

Table 2 (READ-R Model) shows how Factor 1 corresponds to the items that include the Family Cohesion factor on the scale. This Factor 1 is comprised of six items, all of them with loadings of 0.59 , which explain $33.79 \%$ of the variance. Factor 3 comprises four items and forms the Social Resources component, explaining $7.86 \%$ of the variance. Factor 4 has three items which are some of the items from the Social Competence factor $(8,9$ and 10) and explain $5.76 \%$ of the variance. Factor 2 has six items corresponding to Orientation toward Goals and the Personal Component factor is made up of Items 12, 13 and 14, explaining 10.59\% of variance. Finally, Factor 5, comprises three items, each of them a factor different from the original scale.

3.3. Confirmatory Factor Analysis of the Resilience Scale for Adolescents (READ), READ-R and READ-4R Models

Table 3 compares the models analyzed, showing how the original READ model is the one which fits the best (Figure 2). 
Table 3. Fit indices for the models proposed $(n=605)$

\begin{tabular}{|c|c|c|c|c|c|c|c|}
\hline \multirow{3}{*}{ Model } & \multirow{3}{*}{$\chi^{2}(\mathrm{df})$} & \multirow{3}{*}{$\chi^{2} / \mathrm{df}$} & \multirow{3}{*}{ CFI } & \multirow{3}{*}{ TLI } & \multicolumn{3}{|c|}{ RMSEA } \\
\hline & & & & & \multirow{2}{*}{ Est. } & \multicolumn{2}{|c|}{$\mathrm{IC} 90 \%$} \\
\hline & & & & & & Below. & Above \\
\hline Original READ Model & 415.548 (199) & 2.088 & 0.923 & 0.901 & 0.059 & 0.051 & 0.067 \\
\hline Unidimensional READ Model & 1186.749 (209) & 5.678 & 0.650 & 0.576 & 0.122 & 0.115 & 0.128 \\
\hline Proposed READ-R Model & 421.648 (199) & 2.118 & 0.92 & 0.899 & 0.060 & 0.052 & 0.067 \\
\hline Proposed $R E A D-4 R$ Model & $454.209(203)$ & 2.237 & 0.910 & 0.888 & 0.063 & 0.055 & 0.070 \\
\hline
\end{tabular}

Note. CFI = Comparative fit index; TLI = Tucker-Lewis index; RMSEA = Root mean square error of approximation; $\mathrm{CI}=$ Confidence interval; $\mathrm{df}=$ Degrees of freedom; Est. = Estimation .

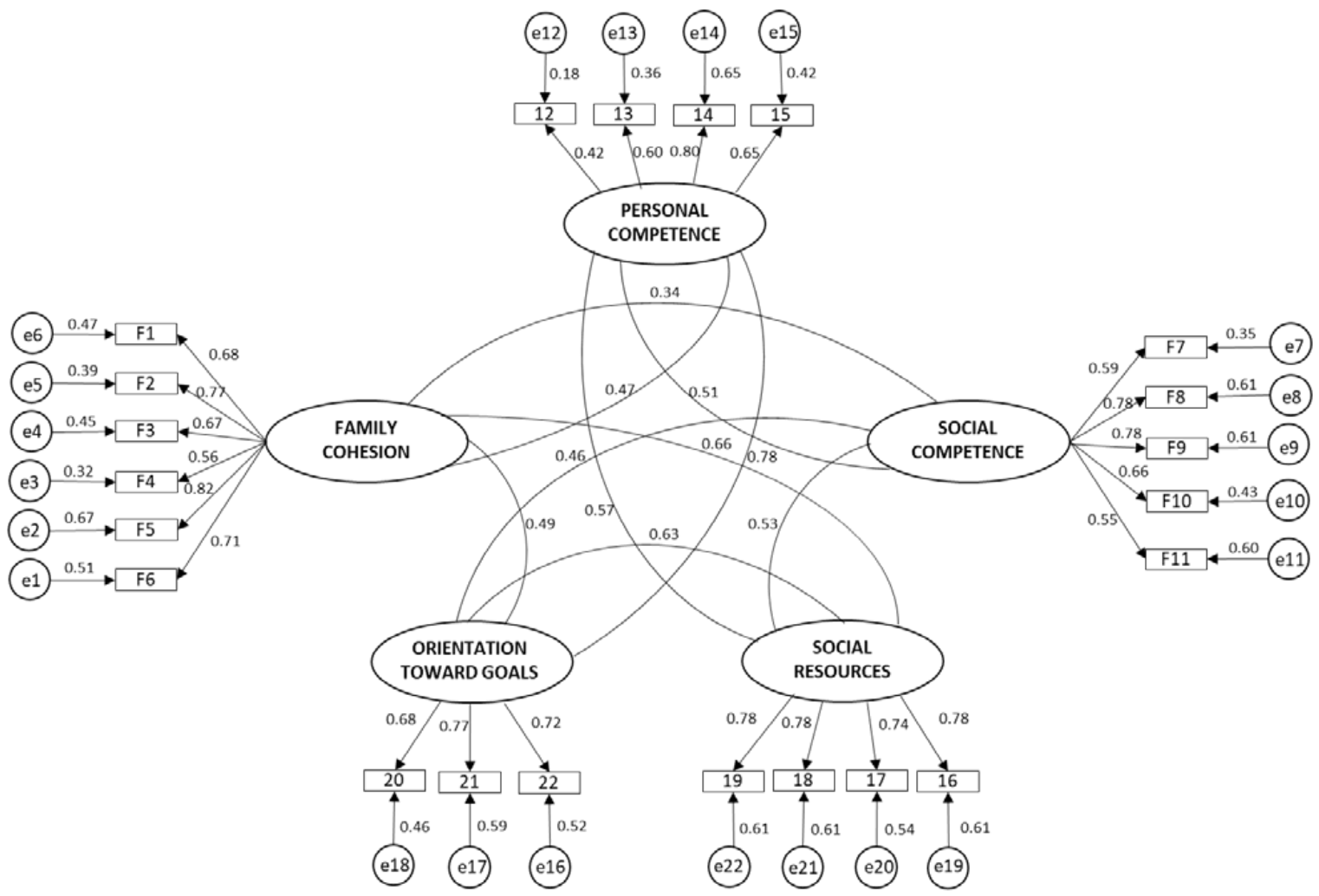

Figure 2. Original READ model $(N=317)$.

Table 4 shows the values for the five different models, where the $\Delta$ CFI is below 0.01 in all of them, accepting configural, metric, scalar and strict invariance.

Table 4. Multigroup analysis of invariance across gender (male/female).

\begin{tabular}{ccccccccc}
\hline Model & $\chi^{\mathbf{2}}$ & $\mathbf{d f}$ & $\chi^{\mathbf{2}} / \mathbf{d f}$ & $\Delta \boldsymbol{\chi}^{\mathbf{2}}$ & $\mathbf{C F I}$ & $\Delta$ CFI & IFI & RMSEA (IC 90\%) \\
\hline M0a (male) & $652.949(p=0.000)$ & 398 & 1.640 & & 0.909 & & 0.885 & $0.045(0.039-0.051)$ \\
M0b (female) & $685.936(p=0.000)$ & 415 & 1.652 & & 0.957 & & 0.957 & $0.032(0.028-0.036)$ \\
M1 (base model) & $733.694(p=0.000)$ & 437 & 1.678 & & 0.909 & - & 0.885 & $0.045(0.039-0.051)$ \\
M2 (FS) & $776.207(p=0.000)$ & 459 & 1.691 & 0.013 & 0.909 & - & 0.885 & $0.045(0.039-0.051)$ \\
M3 (FS + Int) & $799.971(p=0.000)$ & 474 & 1.687 & 0.009 & 0.909 & - & 0.885 & $0.045(0.039-0.051)$ \\
M4 (FS + Int + Err) & $652.949(p=0.000)$ & 398 & 1.640 & 0.038 & 0.909 & - & 0.885 & $0.045(0.039-0.051)$ \\
\hline
\end{tabular}

Note: $\mathrm{SF}=$ Factor saturations, Int $=$ Intercepts, Err $=$ Errors.

\section{Discussion}

The interest that resilience has awakened in recent years is due to the possibility of being able to identify the protective factors necessary for proper adaptation and prevention of psychological 
problems $[8,13]$. This study validated the READ in an adolescent Spanish population as an appropriate scale for evaluating the factors of resilience.

The following conclusions may be arrived at from the factor analyses performed. In the first place, in the exploratory analysis, the items were distributed into four factors that produced the READ-4R model. However, since the original structure was composed of five factors, the READ-R model was designed, in which the distribution of items and factors were different from the original model. Confirmatory factor analyses showed better fit of the original READ model than the two proposed models analyzed. Thus, the scale would comprise five factors, which would be personal competence (made up of four items), social competence (comprised of five items), family cohesion (six items), social resources (composed of four items) and orientation toward goals (which is made up of three items), just as with other previous validations in Italian and Norwegian adolescents $[36,38,40]$. Furthermore, configural, metric, scalar and strict invariance were accepted for all five models, including the analysis of variance across gender. Therefore, good fit and consistency were found for the model in the validation sample. The factorial structure proposed in the resilience scale for Spanish adolescents is the same as that proposed for the Mexican population [39]. This reflects the importance of the validation of instruments in different cultures and societies. Moreover, it should be considered what the instrument chosen evaluates, since there are different questionnaires evaluating resilience, but each one focuses on one aspect [41] providing different results.

At the same time, there is scientific evidence of the predictive value of READ for signs of depressive symptoms in adolescent populations, as this scale can evaluate the factors for protection from these symptoms and use them as a predictor of a good state of health [32]. According to Ruvalcaba-Romero et al. [39], the predictive value of this scale is very useful in Mexican youths, given the high prevalence of depressive symptoms in this population.

\section{Conclusions}

The Spanish adaptation of the READ can be very useful as a brief instrument for determining the factors of resilience quickly due to the number of items. This validation can serve for the creation of tools and action focused on each of the factors for preventing or intervening in adolescents. These tools should be especially directed at improving the personal competency that is part of individual psychosocial adjustment and facilitates coping with adversity. As mentioned above, according to other studies, finding a sample of resilient adolescents who have experienced an important stressful factor in their lives, and who have been able to cope with it, led to differentiation in the specific characteristics of the individuals, as well as in resilience levels. In addition, this questionnaire enabled, in other areas, a contribution to the process of positive adaptation in adolescence.

In future research, a larger Spanish sample would be necessary to widen the discussion of results, and comparative analyses in different social and cultural contexts, in addition to testing whether all the factors develop the same way.

Author Contributions: M.d.M.M.J., M.d.C.P.-F., I.M.R., and A.B.B.M. contributed to the conception and design of the review. J.J.G.L. applied the search strategy. All authors applied the selection criteria. All authors completed the assessment of bias risk. All authors analyzed and interpreted the data. M.d.M.M.J., M.d.C.P.-F., and A.B.B.M. wrote this manuscript. M.d.C.P.-F. and J.J.G.L. edited this manuscript. M.d.M.M.J. is responsible for the overall project. All authors have read and agreed to the published version of the manuscript.

Funding: This research received no external funding.

Acknowledgments: Part of this work has been developed thanks to the financing of the University of Almería, which contributed to the hiring of research personnel in predoctoral training, which was granted to Ana Belén Barragán Martín.

Conflicts of Interest: The authors declare no conflict of interest. 


\section{References}

1. Cutrín, O.; Gómez-Fraguela, J.A.; Maneiro, L.; Sobral, J. Effects of parenting practices through deviant peers on nonviolent and violent antisocial behaviours in middle- and late-adolescence. Eur. J. Psychol. Appl. Legal Context 2017, 9, 75-82. [CrossRef]

2. Rodríguez, P.; Matud, M.P.; Álvarez, J. Gender and quality of life in adolescence. J. Behav. Health Soc. Issues 2017, 9, 89-98. [CrossRef]

3. Fuentes, M.; García, F.; Gracia, E.; Alarcón, A. Parental styles of socialization and psychological adjustment. A study with Spanish teenagers. Rev. Psicodidáct. 2015, 20, 117-138. [CrossRef]

4. Gázquez, J.J.; Pérez-Fuentes, M.C.; Molero, M.M.; Barragán, A.B.; Martos, A.; Sánchez-Marchán, C. Drug use in adolescents in relation to social support and reactive and proactive aggressive behavior. Psicothema 2016, 28, 318-322. [CrossRef] [PubMed]

5. Prado, V.; Villanueva, L.; Górriz, A. Trait emotional intelligence and subjective well-being in adolescents: The moderating role of feelings. Psicothema 2018, 30, 310-315. [CrossRef]

6. Tian, L.; Wang, D.; Huebner, E.S. Development and validation of the Brief Adolescents' Subjective Well-Being in School Scale (BASWBSS). Soc. Indic. Res. 2015, 120, 615-634. [CrossRef]

7. Vega, M.T. Modelo sociocognitivo de la satisfacción vital en personas con enfermedad crónica [Sociocognitive model of life satisfaction in people with chronic disease]. Eur. J. Investig. Health Psychol. Educ. 2018, 8, 157-167. [CrossRef]

8. Olsson, C.A.; Bond, L.; Burns, J.M.; Vella-Brodrick, D.A.; Sawyer, S.M. Adolescent resilience: A concept analysis. J. Adolesc. 2003, 26, 1-11. [CrossRef]

9. Masten, A.S. Ordinary magic: Resilience processes in development. Am. Psychol. 2001, 56, $227-238$. [CrossRef]

10. Bonanno, G.A. Uses and abuses of the resilience construct: Loss, trauma, and health-related adversities. Soc. Sci. Med. 2012, 74, 753-756. [CrossRef]

11. Rodríguez-Fernández, A.; Ramos-Díaz, E.; Madariaga, J.M.; Arrivillaga, A.; Galende, N. Steps in the construction and verification of an explanatory model of psychosocial adjustment. Eur. J. Educ. Psychol. 2016, 9, 20-28. [CrossRef]

12. Seward, R.J.; Bayliss, D.M.; Ohan, J.L. The Children's Social Vulnerability Questionnaire (CSVQ): Validation, relationship with psychosocial functioning, and age-related differences. Int. J. Clin. Health Psychol. 2018, 18, 91-188. [CrossRef] [PubMed]

13. Hjemdal, O.; Friborg, O.; Stiles, T.C.; Martinussen, M.; Rosenvinge, J. A new scale for adolescents resilience: Grasping the central protective resources behind healthy development. Meas. Eval. Couns. Dev. 2006, 39, 84-96. [CrossRef]

14. Amstadter, A.B.; Moscati, A.; Maes, H.H.; Myers, J.M.; Kendler, K.S. Personality, cognitive/psychological traits and psychiatric resilience: A multivariate twin study. Personal. Individ. Differ. 2016, 91, 74-79. [CrossRef]

15. Villasana, M.; Alonso-Tapia, J.; Ruiz, M. A model for assessing coping and its relation to resilience in adolescence from the perspective of "person-situation interaction". Personal. Individ. Differ. 2016, 98, 250-256. [CrossRef]

16. Wright, M.; Masten, A.S.; Narayan, A.J. Resilience processes in development: Four waves of research on positive adaptation in the context of adversity. In Handbook of Resilience in Children; Goldstein, S., Brooks, R.B., Eds.; Springer Science: New York, NY, USA, 2013; pp. 15-37.

17. Molero, M.M.; Pérez-Fuentes, M.C.; Carrión, J.J.; Luque, A.; Garzón, A.; Martos, A.; del Mar Simón, M.; Barragán, A.B.; Gázquez, J.J. Antisocial behavior and interpersonal values in high school students. Front. Psychol. 2017, 8, 170. [CrossRef]

18. Pérez-Fuentes, M.C.; Gázquez, J.J.; Mercader, I.; Molero, M.M.; García, M.M. Rendimiento académico y conductas antisociales y delictivas en alumnos de Educación Secundaria Obligatoria [Academic Achievement and Antisocial Behavior in Public Secondary Education Students]. Rev. Int. Psicol. Ter. Psicol. 2011, 11, 401-412.

19. Rodríguez-Fernández, A.; Ramos-Díaz, E.; Ros, I.; Fernández-Zabala, A.; Revuelta, L. Bienestar subjetivo en la adolescencia: El papel de la resiliencia, el autoconcepto y el apoyo social percibido [Subjective well-being in adolescence: The role of resilience, self-concept and perceived social support]. Suma Psicológica 2016, 23, 60-69. [CrossRef] 
20. Villasana, M.; Alonso-Tapia, J.; Ruiz, M. Procesos de afrontamiento y factores de personalidad como predictores de la resiliencia en adolescentes: Validación de un modelo structural [Coping Processes and Personality Factors as Predictors of Resilience in Adolescent Students: Validation of a Structural Model]. Revista Psicodidáctica 2017, 22, 93-101. [CrossRef]

21. Arrogante, O. Mediación de la resiliencia entre burnout y salud en el personal de Enfermería [Mediation of the resilience between burnout and health in Nursing staff]. Enfermería Clínica 2014, 24, 283-289. [CrossRef]

22. Simón-Saiz, M.J.; Fuentes-Chacón, R.M.; Garrido-Abejar, M.; Serrano-Parra, M.D.; Larrañaga-Rubio, E.; Yubero-Jiménez, S. Influencia de la resiliencia sobre la calidad de vida relacionada con la salud en adolescentes [Influence of resilience on health-related quality of life in adolescents]. Enfermería Clínica 2018, 28, 283-291. [CrossRef] [PubMed]

23. González, N.I. Resiliencia y Personalidad en Niños y Adolescentes. Cómo Desarrollarse en Tiempos de Crisis [Resilience and Personality in Children and Adolescents. How to Develop in Times of Crisis]; Universidad Autónoma del Estado de México: México City, Mexico, 2011.

24. Gaxiola, J.C.; Frías, M.; Hurtado, M.F.; Salcido, L.C.; Figueroa, M. Validación del Inventario de Resiliencia (IRES) en una muestra del Noreste de México [Validation of the Resilience Inventory (IRES) in a sample from Northeast Mexico]. Enseñanza Investigación Psicología 2011, 16, 73-83.

25. Cantero-García, M.; Alonso-Tapia, J. Brief Resilience Scale in front children's Behavior Problems (BRS-BP). Anales Psicología 2018, 34, 531-535. [CrossRef]

26. Connor, K.M.; Davidson, J.R. Development of a new resilience scale: The Connor-Davidson Resilience Scale (CD-RISC). Depress. Anxiety 2003, 18, 76-82. [CrossRef] [PubMed]

27. Yu, X.N.; Lau, J.T.F.; Mak, W.W.S.; Zhang, J.; Lui, W.W.S.; Zhang, J. Factor structure and psychometric properties of the Connor-Davidson Resilience Scale among Chinese adolescents. Compr. Psychiatry 2011, 52, 218-224. [CrossRef]

28. Serrano, M.D.; Garrido, M.; Notario, B.; Bartolomé, R.; Solera, M.; Martínez, V. Validez de la escala de resiliencia de Connor-Davidson (10 ítems) en una población de mayores no institucionalizados [Validity of the Connor-Davidson resilience scale (10 items) in a population of non-institutionalized seniors]. Enfermería Clínica 2013, 23, 14-21.

29. Campbell-Sills, L.; Stein, M.B. Psychometric analysis and refinement of the Connor-Davidson Resilience Scale (CD-RISC): Validation of a 10-item measure of resilience. J. Trauma. Stress 2007, 20, 1019-1028. [CrossRef]

30. Notario-Pacheco, B.; Solera-Martínez, M.; Serrano-Parra, M.; Bartolomé-Gutiérrez, R.; García-Campayo, J.; Martínez-Vizcaíno, V. Reliability and validity of the Spanish version of the 10-item Connor-Davidson Resilience Scale (10-item CD-RISC) in young adults. Health Qual. Life Outcomes 2011, 9, 63-69. [CrossRef]

31. Pozuelo-Carrascosa, D.P.; Martínez-Vizcaíno, V.; Sánchez-López, M.; Bartolomé-Gutiérrez, R.; Rodríguez-Martín, B.; Notario-Pacheco, B. Resilience as a mediator between cardiorespiratory fitness and mental health-related quality of life: A cross-sectional study. Nurs. Health Sci. 2017, 19, 316-321. [CrossRef]

32. Hjemdal, O.; Aune, T.; Reinfjell, T.; Stiles, T.C.; Friborg, O. Resilience as a predictor of depressive symptoms: A correlational study with young adults. Clin. Child Psychol. Psychiatry 2007, 12, 91-104. [CrossRef]

33. Méndez, I.; García-Sevilla, J.; Martínez, J.P.; Bermúdez, A.M.; Pérez, P.; García-Munuera, I. Alexitimia, resiliencia y creencias paranormales en personas mayores en un centro institucionalizado [Alexithymia, resilience and paranormal beliefs in older people in an institutionalized center]. Eur. J. Investig. Health Psychol. Educ. 2015, 5, 209-219. [CrossRef]

34. Vizoso-Gómez, C.; Arias-Gundín, O. Resiliencia, optimismo y burnout académico en estudiantes universitarios [Resilience, optimism and academic burnout in university students]. Eur. J. Educ. Psychol. 2018, 11, 47-59. [CrossRef]

35. González, N.I. Autoestima, optimismo y resiliencia en niños en situación de pobreza [Self-esteem, optimism and resilience in children in poverty]. Revista Internacional Psicología 2018, 16, 1-13. [CrossRef]

36. Von Soest, T.; Mossige, S.; Stefansen, K.; Hjemdal, O. A Validation Study of the Resilience Scale for Adolescents (READ). J. Psychopathol. Behav. Assess. 2010, 32, 215-225. [CrossRef]

37. Windle, G.; Bennett, K.M.; Noyes, J. A methodological review of resilience measurement scales. Health Qual. Life Outcomes 2011, 9, 2-18. [CrossRef] 
38. Stratta, P.; Riccardi, I.; Di Cosimo, A.; Cavicchio, A.; Struglia, F.; Daneluzzo, E.; Capanna, C.; Rossi, A. A validation study of the italian versión of the resilience scale for adolescents (READ). J. Community Psychol. 2012, 40, 479-485. [CrossRef]

39. Ruvalcaba-Romero, N.; Gallegos-Guajardo, J.; Villegas-Guinea, D. Validation of the resilience scale for adolescents (READ) in Mexico. J. Behav. Health Soc. Issues 2015, 6, 21-34. [CrossRef]

40. Sivertsen, B.; Harvey, A.G.; Pallesen, S.; Hysing, M. Mental health problems in adolescents with delayed sleep phase: Results from a large population-based study in Norway. J. Sleep Res. 2015, 24, 11-18. [CrossRef]

41. Gartland, D.; Bond, L.; Olsson, C.A.; Buzwell, S.; Sawyer, S.M. Development of a multi-dimensional measure of resilience in adolescents: The Adolescent Resilience Questionnaire. BMC Med. Res. Methodol. 2011, 11, 134. [CrossRef]

42. Marici, M. Some psychometric properties of the family domain in the "Adolescent Resilience Questionnaire". Procedia Soc. Behav. Sci. 2015, 187, 289-294. [CrossRef]

43. Guilera, G.; Pereda, N.; Paños, A.; Abad, J. Assessing resilience in adolescence: The Spanish adaptation of the Adolescent Resilience Questionnaire. Health Qual. Life Outcomes 2015, 13, 100. [CrossRef] [PubMed]

44. Cheraghi, M.A.; Ebadi, A.; Gartland, D.; Ghaedi, Y.; Khoshnavay, F. Translation and validation of "Adolescent Resilience Questionnaire" for Iranian adolescents. Asian J. Psychiatry 2017, 25, 240-245. [CrossRef] [PubMed]

45. Sahin, H.; Karatas, Z. Validity and reliability of the resilience scale for early adolescents. Procedia Soc. Behav. Sci. 2014, 131, 458-464. [CrossRef]

46. Finney, S.J.; di Stefano, C. Non-normal and categorical data in structural equation modeling. In Structural Equation Modeling: A Second Course; Hancock, G.R., Mueller, R.O., Eds.; Information Age: Greenwich, CT, USA, 2006; pp. 269-314.

47. Bentler, P. EQS Structural Equations Program Manual; BMDP Statistical Software: Los Angeles, CA, USA, 1989.

48. Hair, J.; Black, B.; Babin, B.; Anderson, R.E.; Tatham, R.L. Multivariate Data Analysis, 6th ed.; Pearson: London, UK, 2006.

49. Cronbach, L.J. Coefficient alpha and the internal structure of tests. Psychometrika 1951, 16, 297-334. [CrossRef]

50. Byrne, B.M.; Stewart, S.M. The MACS approach to testing for multigroup invariance of a second-order structure: A walk through the process. Struct. Equ. Model. 2006, 13, 287-321. [CrossRef]

51. Cheung, G.W.; Rensvold, R.B. Evaluating goodness-of-fit indexes for testing measurement invariance. Struct. Equ. Model. 2002, 9, 233-255. [CrossRef] 